\title{
How to Use Activities to Realize the Self-Management of Middle School Students?
}

\author{
Weijie Meng, Fengqi Ning \\ Nanjing Yutong Experimental School, Nanjing 211100, Jiangsu, China
}

\begin{abstract}
Cultivating students' self-management ability is the requirement of social development and the progress of the times to school education, and it is also the need for students' growth. For middle school students in adolescence and undergoing tremendous changes in their body and mind, its significance is even more prominent. As an element of direct contact with students, activities play an irreplaceable role in cultivating students' self-management ability. Nanjing Yutong Experimental School has added a selfmanagement course to its teaching plan. Through the development of diversified activities, goals are achieved in specific activities, and the overall development of students has been completed. Taking the school's practical activities as an example, this paper attempted to use the concept of activity teaching to explain better how the school develops self-management of middle school students based on students' development and creates activities suitable for students' growth to realize better students realize self-management in activities.
\end{abstract}

Science Insights Education Frontiers 2021; 9(2):1305-1318.

Doi: 10.15354/sief.21.re046

How to Cite: Meng, W., \& Ning, F. (2021). How to use activities to realize the self-management of middle school students? Science Insights Education Frontiers, 9(2):1305-1318.

Keywords: Activities, Teaching, Middle School Students, Self-Management 
Meng \& Ning. Activities and the Self-Management of Middle School Students.

About the Author: Weijie Meng, Principal of Nanjing Yutong Experimental School, 22 Jiangjun Avenue, Jiangning District, Nanjing 211100, Jiangsu, China.E-mail:13608955415@126.com

Correspondence to: Fengqi Ning, Nanjing Yutong Experimental School, 22 Jiangjun Avenue, Jiangning District, Nanjing 211100, Jiangsu, China. E-mail:872225979@qq.com

Conflict of Interests: None.

(C) 2021 Insights Publisher. All rights reserved.

(c) (i) (-) Creative Commons Non Commercial CC BY-NC: This article is distributed under the terms of the Creative Commons Attribution-NonCommercial 4.0 License (http://www.creativecommons.org/licenses/by$\mathrm{nc} / 4.0 /$ ) which permits non-commercial use, reproduction and distribution of the work without further permission provided the original work is attributed by the Insights Publisher. 


\section{Introduction}

ELF-management is a skill that allows people to control their thoughts, emotions, and actions. The ability of self-management is reflected in assessing problems, setting goals, and monitoring the time and environmental factors that hinder the achievement of goals (Frayne, 1991). This concept was initially applied in management through the distribution and transfers of responsibilities and authorities so that individuals at all levels in a large community can give full play to their initiative and jointly promote goals. Later, the concept of self-management gradually shifted to many aspects such as health, psychology, and social interaction and progressively expanded the idea of extension.

As many countries in the world began educational reforms in the 1980 s, educational methods have gradually changed. Self-management has steadily been applied in education because it emphasizes the survival and development of individuals. Unlike the management field that produced this concept, its research and application in the education field are more inclined to cultivate students' self-management ability (Meng \& Ning, 2021).

Since implementing the new curriculum reform at the beginning of the $21 \mathrm{st}$ century, China has developed students' comprehensive quality and emphasized autonomy. Therefore, the school must implement student self-management, allowing students to actively adjust the plan based on their situation and learning status and ultimately achieve their goals, thereby promoting the joint development of individual students and the school. In the specific implementation process, establishing goals, creating content and creating activities are the necessary foundations and conditions to ensure the success of students' self-management (Li, 2011). Among them, activity, as the fundamental way of human existence and development, realizes human needs or goals through the transformation of the surrounding reality and is the basis of individual development. Furthermore, as the essential existence of activities, the education and teaching system enriches the activity's connotation, carries forward the activity teaching in it, and realizes the construction of the activity teaching system. Therefore, activities as the basic unit of activity teaching should become the basic structure of activity teaching, provide practical entry points for promoting students' all-round development, and provide essential support for developing and constructing students' self-management (Wang, 2010).

In addition, from a philosophical point of view, the essence of selfmanagement is "socialized management based on communicative practice, which must be able to meet people's needs for self-realization, reflect their free personality, and enrich their social relationships." Unfortunately, in the school environment, the "practice of communication" is relatively single, so the ability of students to be cultivated in the traditional teaching environment is also limited" (Wang \& Pan, 2006). Therefore, to expand students' abilities, especially self-management abilities based on autonomy, it is 
necessary to construct a suitable environment to develop fully. Therefore, rich activities are of great significance for cultivating students' self-management ability.

Based on previous studies, this research will in-depth explore the mechanism of activities for students' self-management from the perspective of the significance and role of activity teaching in cultivating students' self-management ability, combined with the practical experience of Nanjing Yutong Experimental School. Thus, it helps develop more educational value in activities and provides reference and reference for educational practitioners.

\section{Literature Review}

The idea of "active teaching" in the history of world education can be traced back to the European Renaissance. Its purpose is to oppose rigorous book learning and allow children to accumulate knowledge and experience through various practical activities such as observation, investigation, play, and labor (Tian, 1998). After that, this spirit continued to develop in the modern romantic education thought represented by Rousseau. Educators advocated that education should adapt to students' natural development and that all knowledge obtained from experience should be obtained from practice instead of books (Noone, 1972). Fröbel (1895) also put forward the idea of promoting the free, collaborative, and multi-faceted development of the inner nature of children. Under this idea, play, homework, labor, and object teaching have been integrated into teaching methods.

In the first half of the 20th century, the educational idea of "learning by doing" was put forward with Dewey's system. The role of school education has been expanded. In addition to imparting knowledge, there is also the transfer, exchange, and development of experience (Dewey, 1938). His thinking has developed more in contemporary times. On the one hand, Piaget proposed that "people's understanding of objects begins with their activities on objects" from the cognitive level. Activities provide essential support for accumulating knowledge and the development of thinking (Piaget, 1982). On the other hand, the Soviet Union Vygotsky and other scholars introduced the Marxist concept of "practice" into teaching. They proposed that humans improve their development by practicing the subject to the object (Toomela, 2008).

Soviet psychologist A.N. Leontyev (1903-1979) made a systematic study of activities. In the book "Soviet Psychology," edited and published by R.B. Winn in 1961, Leontyev defined activity as the sum of various actions united by a common purpose to complete a particular social function. He believes that the generation of personality is not a natural process. Instead, the result of the behavior is related to the social relationship. In this process, education is a crucial factor. Then put forward the doctrine of activity theory, consciousness theory, and psychological personality characteristics (Winn, 1961). Under his influence, researchers began to focus on activities from the outside to the inside, paying particular attention to the nature of the activities.

Activity teaching in China started relatively late. Xingzhi Tao's "life education" proposed in the 1920s and 1930s, was considered the source of China's exploration of 
activity education (Tao, 2018). Subsequently, Heqin Chen proposed the practice of "activity education" (Zhu, 2013). Until the early 1990s, the Chinese Education Commission included activity courses in the nine-year compulsory education curriculum plan, marking the widespread recognition of the concept of "activity teaching" in the domestic education system. Its purpose is to explore a new teaching model and the traditional teaching methods characterized by knowledge-based, teacher-centered, imparting, and instillation to better develop their subjectivity in a diversified learning model (Yang, 1999).

Judging from the current research in China, the recent research on activity education focuses on designing educational activities in venues and campus language applications. However, the teaching significance of campus cultural festivals and agricultural education activities frequently launched in China's secondary education has not yet been explored. Therefore, these activities have not been effectively designed on the educational level. In the design of the school's self-management activities, Nanjing Yutong Experimental School bases itself on the educational function of the activities, gives full play to its advantages, and makes up for the limitations of the traditional education model.

\section{Activity Teaching Practice in Nanjing Yutong Exper- imental School}

The "activity" in teaching has a specific connotation. It is different from human activity in the general sense-labor and different from "activity" in traditional schooling. It emphasizes students' autonomous participation, a practical activity based on students' learning interest and internal needs, characterized by active exploration, transformation, and transformation of activity objects, and aimed at achieving the comprehensive development of students' primary abilities (Zhong, 2005).

Since the beginning of 2014, Nanjing Yutong Experimental School has been based on the development needs of students, absorbing advanced theoretical knowledge, and constantly innovating educational management methods. They have built a set of management methods for students' independent experience, independent development, and independent innovation, covering all the contents of students' school and school, life, and activities. In creating activities, the school is based on student development and has designed various activities for students from the two dimensions of inside and outside the school. Help students realize self-design, self-regulation, and self-evaluation in activities. In the end, students will continuously improve their sense of autonomy and self-help growth in experience and practice, form excellent social citizenship, and move towards self-education.

\section{Development of Off-Campus Activities}

\section{- "Four Festivals and One Party"}


"Four Festivals and One Party" is a campus activity designed by Nanjing Yutong Experimental School to cultivate students' self-management ability. It consists of a sports food festival, a science and technology festival, a reading festival, an art festival, and a New Year's Day party. These activities have a longer time dimension, and students should make their activity plans to ensure full participation as much as possible.

\section{(i) Sports Food Festival}

This activity is set up to cultivate students' awareness of health management, integrating physical exercise and healthy eating. It is hoped that students can transfer their emphasis on these two aspects from activities to daily life.

The preparation period for the course activities is six weeks. The festival is the final presentation form of the course. In the six weeks of preparation, students need to complete the goal setting for sports and diet items, preparation of activity materials, drafting evaluation standards, and setting up activities scenes under the guidance of teachers. It integrates many elements of cultivating students' self-management ability, such as goal setting and progress control. This process allows students to understand that the formation of goals is not accomplished overnight in a management process. It can be gradually finalized through repeated adjustments and become a feasible target. The consciousness formed through the activity is transferred to the students' understanding of the setting of learning goals through the teacher's guidance. It can also look at the goal-setting from a more objective and rational perspective in the learning process and work hard to achieve the goal.

\section{(ii) Science and Technology Festival}

The design idea of this activity is to refer to popular science images, basic science experiments, and knowledge in the classroom. It provides a concrete perceptual realization of abstract knowledge in the school and enhances students' understanding of science and technology intangible and sensible practical activities.

The activity consists of four sections: science popularization, experimentation, production, and competition. Set different content according to different school stages. The design of science popularization and investigation echoes the knowledge points encountered in each school's mathematics, physics, biology, and chemistry classes to extend the classroom knowledge in campus activities. In each type of activity, teachers set up significant themes, such as introducing students to building block robots and artificial intelligence applications in education and other fields. This allows them to establish basic concepts for the frontier applications of science and introduce more abstract projects such as cloud computing to explore.

The part of the experimental design is benchmarked against the level of science knowledge in each section. The activity design allows students to enter the knowledge situation, stimulate their curiosity, let their spontaneous thirst for knowledge drive them, and take the initiative to obtain knowledge. Then build the concept of students' selfmanagement of learning progress, make it clear that the effectiveness of their self- 
management is closely related to their learning motivation, and integrate this awareness into daily learning.

\section{(iii) Reading Festival}

The reading festival activities aim to broaden students' reading range, cultivate students' reading interest, and at the same time build a scholarly campus with a good reading atmosphere. First of all, the establishment of reading festival activities is to expand students' knowledge of books. In this link, the school has designed a number of readingthemed sections. Furthermore, by guiding students to understand the world's diversity in books, students will be inspired to read independently.

Secondly, it is to cultivate students' comprehensive reading ability. The reading festival includes reading books and the appreciation and analysis of film and television works adapted from literary classics, recitations, and calligraphy. The scope of employment is not only Chinese books but also English works. Through such a comprehensive introduction and stimulating activities, students gradually realize the world's diversity in books during their participation in the activities, forming the habit of reading and exploring.

\section{(iv) Art Festival}

The art festival is held in the hope of using the spiritual value of art to adjust, improve, enrich, and develop students' spiritual lives and improve students' spiritual quality. The activity time is six weeks. At the same time, it includes two categories of music and fine arts and comprehensively enhances students' artistic aesthetic ability, artistic perception ability, and individualized expression ability.

Music and images are different means of expressing life than words. Text is frequently used by students, while music and images are often not the first choices. The school strives to cultivate students' perception of the environment and diversified performance capabilities in the art festival. Self-management puts forward requirements for the individual's ability to perceive the environment. The use of artistic means to express life promotes students' observation and description of the environment to cultivate students' ability to recognize the environment.

\section{- Study Trip Activities}

The school has designed research trip activities for students of different stages to broaden their horizons and integrate knowledge. The destinations include the Crater Sapphire Museum with the theme of understanding natural landscapes and the Dongying Yellow River Delta Wetland Museum. In addition, there are memorial halls of Menglianggu and Yantai Haiyang Landmine Warfare for historical themes. In addition, they travel to cities such as Qingdao and Zibo that have built a comprehensive understanding of the region. 
Study Trip Activities are the training and test of comprehensive abilities such as student life management, collective awareness, and knowledge accumulation. In this activity, students need to coordinate the relationship between personal rhythm of life and group activities and mobilize the knowledge acquired in school during the activity, such as plate movement, geological structure, Menglianggu battle, paleontological activity trajectory, and so on. If students do not bring knowledge from the classroom to life well, they need teachers to guide them in research and study to promote the awareness that the knowledge formed by students is comprehensive in life. Classroom knowledge provides a medium for understanding the world. In real life, actors need to use existing knowledge and learning ability to acquire new knowledge spontaneously. This process of active learning is also the process of mobilizing self-management consciousness.

\section{- 65 km Hiking and Training Activities}

The $65 \mathrm{~km}$ is a challenge to design for students within the range of their physical abilities. It aims to repeatedly strengthen their will by allowing students to complete a seemingly tricky goal; simultaneously, they build their cognition. Many students question their abilities when they see goal setting, thinking that the task is impossible to complete. However, they have spontaneously mobilized their physical management ability and judge the external environment to achieve their goals in actual actions.

Although hiking and training activities are external goals, teachers can only give students a certain amount of spiritual encouragement and strategic guidance in this kind of physical activity. The actual process of achieving the goal is entirely dependent on the students' self-management. This is a very effective process of mobilizing students' self-management ability. Due to the irreplaceability of the main body of physical activity, training in such activities may be more effective than the self-management awareness deliberately cultivated in classroom learning.

After the activity, there is the link of sentiment exchange, which is how the teacher guides the students to transfer this self-management ability from physical fitness to the field of knowledge mastery, ensuring the value of the activity.

\section{- Volunteer Activities and Festival-Themed Activities}

Volunteer activities are designed to promote students' empathy and awareness of serving others. At the middle school stage, students' abilities are limited. They will have the idea of helping others, but they have not established an apparent ability-behavioral awareness. Therefore, schools need to provide a straightforward design and change tasks as the students' ability grows. At the same time, serving others is inspiring students to mobilize existing knowledge and ideas. Strengthen one's cognition through the output of knowledge and skills. The method of helping others places demands on students' sense of responsibility. In this process, students can repeatedly strengthen their sense of responsibility, connect their commitment to others with their duty, and improve their personal qualities in all aspects. 
Festival theme activities aim to cultivate students' sense of social responsibility, encourage students to feel the society, integrate into the times, and build an understanding of the subject in the social background.

A comprehensive inspection of the design of Nanjing Yutong Experimental School in non-teaching activities shows that the school consciously adopts informal learning methods and the construction of the activity environment. They allow students to spontaneously generate interest in knowledge in practice to carry out independent learning and exploration. The school's activity goals are comprehensive, not only to mobilize students to take the initiative to obtain knowledge but also to pursue the overall development of students' bodies and minds. Complete students' living ability, aesthetic consciousness, and self-management ability, these qualities do not have enough room for training in traditional classroom teaching. Therefore, incorporating activity teaching into the school's classic curriculum design enriches the teaching methods and supplements the shortcomings caused by the long-term "cognition-only teaching."

\section{Design of School Activities}

\section{- Realize Student Self-Management through Multi- ple Channels Through the Construction of Classes, Grades, and Clubs}

The school sets up departments for student management roles in classes and grades. First, build a democratic management team based on the self-management team of the course and linked by the student union and the league of associations. Through the training of the school student union, grade student union, class self-management team, and students' project management ability, a complete self-management system has been established from the school student union, grade student union, the class selfmanagement team, to study group leader and house head. This allows each student to participate in various management organizations according to their wishes, build a strong management organization structure where everyone participates, and everyone is responsible, stimulates the enthusiasm for participating in class building, and cultivates the spirit of independent management and responsibility.

\section{(i) Group Building Activities in the Class}

The "Student One Day Standard" is adopted to conduct self-management in the class because they are familiar with this standard. At the same time, a student administrator is set up to assist students in forming a sense of self-management. In the implementation process, this training goal is achieved through group management and on-duty class leader.

Group management is a self-management training model based on the principle of "homogeneity between groups and heterogeneity between groups." Let students with 
different intelligence levels, thinking styles, cognitive styles, and tastes become group members to achieve complementarities of gender, personality, and abilities.

The shift leader on duty is carried out in a post-rotation system. Thus, every student can experience the functions of managers and understand the differences between managers and management objects. In performing management, managers need to regulate students' behavior and record and encourage them to consciously exert their strengths.

When students manage class life and study affairs as managers, they exercise their observation and judgment ability and sense of responsibility and establish their responsibilities. In the process of self-management, students are both managers and objects of management. However, students' daily identities are mostly management objects, and they are relatively unfamiliar with the responsibilities and duties of managers. Therefore, let students manage others first to mobilize their sense of responsibility and action to enhance their self-management ability.

\section{(ii) Grades and Club Activities}

The self-management training has content aimed at students' ability to judge the environment. The environment includes both the natural environment and the social environment. Students' ability to evaluate the natural environment is trained in off-campus activities, while the training to judge the social environment is carried out in the school's student groups.

Compared with daily class activities, student union activities can create collaborative relationships with clear goals. By organizing students to work together for a set goal, students need to judge their abilities, the progress of completing the task, and grasp the situation of others in time, to negotiate and adjust in time to ensure that the goal is achieved as planned. The school holds a plenary meeting of the student congress every semester to vote on proposals and significant resolutions. The implementation of the solutions and recommendations of the student congress should be reported to the representatives and students promptly. Its work status should be announced to the students and subject to student supervision. In addition, the Standing Committee of the Student Congress is responsible for supervising the implementation of the work of the Student Union and the League of Associations and is accountable for their work. The internal meeting of the Standing Committee of the Student Congress is held once a month to discuss work planning.

The Association of Associations shall actively organize research and feedback on the activities of associations once a month. It must not only ensure the effectiveness of club activities but also ensure the discipline of club activities. Furthermore, research and feedback help clubs grow and standardize the domain of student club activities. At the end of the semester, it is necessary to organize the evaluation of clubs, implement the credits for club activities, select high-quality clubs, and promote the development and improvement of campus club activities. 
In the student union and club activities, students have enriched their practical experience and mastered interacting with others, evaluating their environment, and adjusting their status. This realizes the comprehensive development of self-awareness and the improvement of its self-management awareness.

\section{(iii) Cultivate Students' Self-Directed Learning through Classroom Teaching of "Large Unit Holistic Learning"}

The overall learning of the large unit is based on the curriculum standards and the knowledge structure, ability structure, logical structure, value meaning structure of the subject, and the subject's core concepts as the fundamental basis, allowing students to recognize and construct the whole autonomously. This is a learning method for making subject knowledge in activity cognition. The basic understanding of the subject guides its design idea by promoting students to master the basic knowledge while incorporating it into real situations for practice and giving students the autonomy of technique. It allows them to increase their self-management ability while getting knowledge independently.

Although considerable unit learning is traditional cognitive-oriented teaching, the teaching process has been adjusted during this learning process. From the perspective of cultivating students' autonomy, it integrates students' self-preparation before class. Students should self-prepare and complete the guidance plan, and the teacher will teach further knowledge on this basis. The assessment of this learning model is conducted by the student council once a week and once every two weeks for the grade. The survey results are presented in the form of 5 points, 4 points, and 3 points. Thus, the assessment of learning results is more frequent. In addition, the grading mode is flexible, which builds a smaller study period for students to inspect the learning results, which is convenient for students to adjust the learning mode in time to obtain better results.

\section{(iv) Use 271BAY Smart Education Cloud Platform to Provide Support for Students' Self- Management}

In addition to daily activities, the school provides a solid technical guarantee for implementing student self-management through the school-based smart campus cloud platform 271BAY. It is a platform for school students to learn, communicate, evaluate, and grow independently, a platform for teachers and students to share with the outside world, and home-school co-education.

On the one hand, the relevant external high-quality teaching resources on the Internet provided by the 271BAY resource platform and the high-quality teaching resources uploaded by the teachers of 271 Education Group are available for school teachers and students to use. On the other hand, the hierarchical push of 271BAY resources can realize students' personalized hierarchical teaching, conducive to students' 
independent learning. In addition, 271BAY has a record system covering the whole process of learning and growth. Collecting student classroom data, off-class data, life health, and other data support students in establishing a growth model based on data analysis. A diversified, whole-process digital record will dynamically present the development of students, and an evaluation of results will be generated in real-time through the learning network. In this process, parents pay attention to the students' growth dynamics in time, obtain student growth data, and provide a scientific basis for guiding students' growth.

\section{Conclusions}

This article outlines the student self-management carried out by Nanjing Yutong Experimental School on the concept of activity teaching. The school is consciously developing the educational significance of various activities, and the goal of the activities is to cultivate students' comprehensive ability. Therefore, this is not only a supplement to classroom knowledge but also an extension of teaching boundaries.

Campus activities with self-management significance are designed to give each workout a clear training goal, value recognition, responsibility, problem-solving and creative culture. The constructive orientation in the activity design allows the activity subject to complete the self-set goals autonomously and actively during the activation process. Creativity and initiative have sufficient space for development. As Dewey said, "Education is not a matter of 'telling' and being told, but an active and constructive process." The design of these activities emphasizes "proactive" and "constructive."

Most middle schools have a certain amount of campus or off-campus interactive design, such as learning agriculture, campus cultural festivals, etc. They all aim to cultivate certain specific qualities of students, and they also require students to summarize and report on their gains after the activity. However, neither the early-stage activity design nor the mid-term activity implementation has clear regulations, resulting in similar activity items and loose organization of the activation process. When designing activities, the school fully considers the integrity of the development of student's abilities. It constantly improves the guarantee of the campus system to ensure the effectiveness of the activities. Promote students' internal activities (psychology, emotion, will) through external practical activities.

At the same time, we have also discovered some possible problems in our investigation and practice, and these problems have also triggered some thinking. For example, in the presentation of the purpose of the activity, the purpose of the Nanjing Yutong Experimental School needs to be broadened. At present, the school is designing activity items and content with the idea of supplementing the shortcomings of classroom teaching with activities instead of exploring the teaching effectiveness of exclusive activities starting from activities.

In addition, effective activity education requires the cooperation of the activity venue. Places that do not have an evident educational orientation lack practical guidance for students' self-management, which will cause students to participate in activi- 
ties. Still, it is impossible to clarify the self-goal in the activity. Therefore, schools should be more cautious when choosing non-campus activity scenes. The educational facilities of the off-campus activity venues currently selected by the school still need to be improved. There is still room for improvement as an informal learning environment. Schools may consider co-construction with media where activity education is routinely carried out to promote the collaborative and in-depth development of activity education inside and outside the school.

\section{References}

Dewey, J. (1938). Experience and Education. Toronto: Collier-MacMillan Canada Ltd.

Frayne, C. (1991). Reducing employee absenteeism through self-management training: A research-based analysis and guide. New York: Quorum Books.

Fröbel, F. (1895). Friedrich Froebel's Pedagogics of the Kindergarten. D. Appleton.

$\mathrm{Li}, \mathrm{X}$. (2011). Research on the selfmanagement of high school students under the new curriculum reform. Master's Dissertation; Guangxi Normal University). [Chinese] https://kns.cnki.net/KCMS/detail/detail.as px?dbname $=$ CMFD2011\& filename $=1011$ 285312.nh

Meng, W., \& Ning, F. (2021). An evidencebased perspective of the self-management of middle school students. Science Insights, 38 (2):305-313. DOI: https://doi.org/10.15354/si.21.re079

Noone, J.B. (1972). Rousseau's Theory of Natural Law as Conditional. Journal of the History of Ideas, 33(1): 23-42. DOI: https://doi.org/10.2307/2709055

Piaget, J. (1982). Reflections on Baldwin [interview with J.J. Vonèche. In J.M. Broughton \& D.J. Freeman-Moir (Eds.), The cognitive-developmental psychology of James Mark Baldwin. Norwood, NJ: Ablex. pp80-pp86.
Tao, X. (2018). Research on Student Autonomy. Teaching Management and Education Research, 3(7):4-8. [Chinese] https://d.wanfangdata.com.cn/periodical/j xglyjyyj201807003

Tian, H. (1998). Understanding of several theoretical issues of activity teaching. $E d$ ucational Research, 5(4):46-53. [Chinese] http://www.cnki.com.cn/article/cjfdtotaljyyj804.007.htm

Toomela, A (2008). Commentary: Activity theory is a dead-end for methodological thinking in cultural psychology too. Culture \& Psychology. 14(3):289-303. DOI: https://doi.org/10.1177/1354067x0808855 $\underline{8}$

Winn, R. B. (ed.) (1961). Soviet Psychology: A Symposium New York: Philosophical Library.

Yang, L. (1999). The connotation, foundation, and value of activity teaching. Journal of Northeast Normal University (Philosophy and Social Sciences), 44(3):87-91. [Chinese]

http://qikan.cqvip.com/Qikan/Article/Deta il ?id=1002184684

Zhong, Q. (2005). An investigation of the theory of teaching activities. Educational Research, 12(5):36-42+49. [Chinese] http://www.cnki.com.cn/Article/CJFDTot al-JYYJ200505008.htm 
Meng \& Ning. Activities and the Self-Management of Middle School Students.

Zhu, L. (2013). The enlightenment of Heqin Chen's "Activity Education" theory. New Curriculum, 6(1):85. [Chinese]
http://www.cnki.com.cn/Article/CJFDTot al-XKJA201301099.htm

Received: 13 August 2021

Revised: 20 August 2021

Accepted: 24 August 2021 